American Journal of Animal and Veterinary Sciences 4 (3): 49-57, 2009

ISSN 1557-4555

(C) 2009 Science Publications

\title{
Genetic Diversity Analysis of the Gohilwari Breed of Indian Goat (Capra hircus) Using Microsatellite Markers
}

\author{
${ }^{1}$ S. Kumar, ${ }^{2}$ S.P. Dixit, ${ }^{2}$ N.K. Verma, ${ }^{3}$ D.K. Singh, ${ }^{4}$ A. Pande, \\ ${ }^{5}$ S. Kumar, ${ }^{5}$ R. Chander and ${ }^{6}$ L.B. Singh \\ ${ }^{1}$ Molecular Genetics Lab, Ranchi Veterinary College, Kanke, Ranchi, Jharkhand, India \\ ${ }^{2}$ Sr. Scientist (National Bureau of Animal Genetic Resources) Karnal, Haryana, India \\ ${ }^{3}$ Birsa Agricultural University, Kanke, Ranchi, India \\ ${ }^{4}$ College of Biotechnology, Kanke, Ranchi, India \\ ${ }^{5}$ National Bureau of Animal Genetic Resources, Karnal, Haryana, India \\ ${ }^{6}$ Department of Animal Breeding and Genetics, Ranchi Veterinary College, \\ Kanke, Ranchi, Jharkhand, India
}

\begin{abstract}
Problem statement: Gohilwari breed of goat is a multipurpose goat mainly for milk and meat purposes and best suited in its harsh climatic condition. This breed is inadequately characterized till now at DNA level. So the present study was undertaken for population genetic analysis at molecular level to exploit the breed for planning sustainable improvement, conservation and utilization, which subsequently can improve the livelihood of its stake holders. Approach: The experiment was conducted on 50 genomic DNA samples of unrelated goat using 25 microsatellite markers selected from the list suggested by International Society for Animal Genetics (ISAG) and FAO's (DAD-IS). Results: All of the 25 microsatellites were well amplified. The observed number of alleles detected per locus ranged from 4-24 with an overall mean of 10.12 \pm 5.46 . Overall mean observed heterozygosity of 0.505 was lower than the overall mean expected heterozygosity of 0.684 . Most of the loci showed the heterozygote deficit as also depicted by $F_{\text {is }}$ value. There was substantial genetic variation and polymorphism across studied loci in the Gohilwari breed of goat. And this population was not in Hardy-Weinberg equilibrium at most of the studied loci. This population was also receiving new genetic materials through introduction of immigrants. Conclusion: The strong inference that the Gohilwari breed of goat has not undergone bottleneck is also important for goat breeders and conservationists, as it suggests that any unique alleles present in this breed may not have been lost. Therefore, it can be recommended that within-breed diversity is actively maintained to enable these extensively unmanaged stocks to adapt to future demands and conditions and there is ample scope for further improvement in its productivity through appropriate breeding strategies. Though, microsatellites are neutral to selection with Ewens-Watterson test for neutrality some microsatellites were found not neutral or linked to some selective trait that must be further investigated for association to selective traits.
\end{abstract}

Key words: Microsatellite, Gohilwari, goat

\section{INTRODUCTION}

Gohilwari breed of goat is a multipurpose goat mainly reared by the Maldharis (Bharwar and Rabbari communities) for milk and meat purposes. The breed derived its name from the Gohilwad, which was a part of the Kathiawar region and was also the old name of Bhavnagar district of Gujarat state of India. The animals of this goat breed are mainly found in
Junagarh, Amrelli and Bhavnagar districts and also to other adjacent districts of Gujarat. The goats are best fit under the harsh climate conditions of this region. In spite of their ecological and economic importance, the Gohilwari goats are inadequately characterized particularly at DNA level. Microsatellites in particular are useful in conservation genetics because the high degree of polymorphism makes them extremely informative and gives them very high discriminating

Corresponding Author: S. Kumar, Molecular Genetics Lab, Ranchi Veterinary College, Kanke, Ranchi, Jharkhand, India Tel: 919835231325 
American J. Animal \& Vet. Sci., 4 (3): 49-57, 2009

power $^{[12]}$, allowing for a thorough assessment of genetic variation and structure within and among populations ${ }^{[6]}$. Genetic diversity is essential for the long-term survival of the species and populations because it provides the raw material for adoption and evolution, especially when environmental conditions have changed ${ }^{[10,29]}$. A central objective of genetic resources conservation, therefore, is to maintain genetic integrity and natural levels of genetic diversity and to enhance genetic diversity in populations and species where it has been eroded $^{[29]}$. Therefore, to find out within breed genetic diversity a set of twenty five selected microsatellite $s$ have been used. This study has been undertaken to search for the genetic variability, which could be exploited for planning sustainable improvement, conservation and utilization of the breed, which subsequently can improve the livelihood of its stake holders.

\section{MATERIALS AND METHODS}

Isolation of genomic DNA and its amplification through PCR: Genomic DNA was isolated from blood samples of 48 unrelated animals of the breed by the method described by Sambrook et al. ${ }^{[33]}$. A battery of 25 microsatellite markers (Table 1) was selected based on the guideline of ISAG and FAO's DADIS programme to generate data.

Table 1: Microsatellite markers, their sequences, dye labeled, type of repeat, amplified product size, location and accession numbers

\begin{tabular}{|c|c|c|c|c|c|c|}
\hline Locus & Primer sequence & Dye & $\begin{array}{l}\text { Type of } \\
\text { repeat }\end{array}$ & Size range & ${ }^{*}$ Ch. No & $\begin{array}{l}\text { Gen bank } \\
\text { accession No. }\end{array}$ \\
\hline ILST008 & gaatcatggattttctgggg & FAM & $(\mathrm{CA})_{12}$ & $167-195$ & 14 & L23483 \\
\hline ILSTS059 & gctgaacaatgtgatatgttcagg & FAM & $(\mathrm{CA})_{4}(\mathrm{GT})_{2}$ & $105-135$ & 13 & L37266 \\
\hline ETH225 & gatcaccttgccactatttcet & VIC & $(\mathrm{CA})_{18}$ & $146-160$ & 14 & Z14043 \\
\hline ILST044 & agtcacccaaaagtaactgg & NED & $(\mathrm{GT})_{20}$ & $145-177$ & Ann & L37259 \\
\hline ILSTS002 & $\begin{array}{l}\text { tctatacacatgtgctgtgc } \\
\text { cttaggogtotattccaagtoc }\end{array}$ & VIC & $(\mathrm{CA})_{17}$ & $113-135$ & Ann & L23479 \\
\hline OarFCB304 & $\begin{array}{l}\text { cctaggagctttcaataaagaatcgg } \\
\text { coctoctgtcaactgggtcaggg }\end{array}$ & FAM & $\begin{array}{l}(\mathrm{CT})_{11} \\
(\mathrm{CT})_{15}\end{array}$ & 119-169 & Ann & L01535 \\
\hline OarFCB48 & $\begin{array}{l}\text { gagttagtacaaggatgacaagaggcac } \\
\text { gactctagaggatcgcaaagaaccag }\end{array}$ & VIC & (CT) 10 & $149-181$ & 17 & M82875 \\
\hline OarHH64 & $\begin{array}{l}\text { cgttccctcactatggaaagttatatatgc } \\
\text { cactctattgtaagaatttgaatgagagc }\end{array}$ & PET & - & $120-138$ & 4 & $212^{\mathrm{a}}$ \\
\hline OarJMP29 & $\begin{array}{l}\text { gtatacacgtggacaccgctttgtac } \\
\text { gaagtggcaagattcagaggggaag }\end{array}$ & NED & $(\mathrm{CA})_{21}$ & $120-140$ & Ann & U30893 \\
\hline ILSTS005 & $\begin{array}{l}\text { ggaagcaatgaaatctatagcc } \\
\text { tgttctgtgagtttgtaagc }\end{array}$ & VIC & $(\mathrm{nn})_{39}$ & $174-190$ & 10 & L23481 \\
\hline ILSTS019 & $\begin{array}{l}\text { aagggacctcatgtagaagc } \\
\text { acttttggaccctgtagtgc }\end{array}$ & FAM & $(\mathrm{TG})_{10}$ & $142-162$ & Ann & L23492 \\
\hline OMHC1 & $\begin{array}{l}\text { atctggtgggctacagtccatg } \\
\text { gcaatgctttctaaattctgaggaa }\end{array}$ & NED & - & 179-209 & Not reported & $228^{a}$ \\
\hline ILSTS087 & $\begin{array}{l}\text { agcagacatgatgactcagc } \\
\text { ctgcctcttttcttgagagc }\end{array}$ & NED & $(\mathrm{CA})_{14}$ & $142-164$ & Ann & L37279 \\
\hline ILSTS30 & $\begin{array}{l}\text { ctgcagttctgcatatgtgg } \\
\text { cttagacaacaggggtttgg }\end{array}$ & FAM & $(\mathrm{CA})_{13}$ & 159-179 & 2 & L37212 \\
\hline ILSTS34 & $\begin{array}{l}\text { aagggtctaagtccactggc } \\
\text { gacctggtttagcagagagc }\end{array}$ & VIC & $(\mathrm{GT})_{29}$ & $153-185$ & 5 & L37254 \\
\hline ILSTS033 & $\begin{array}{l}\text { tattagagtggctcagtgcc } \\
\text { atgcagacagttttagaggg }\end{array}$ & PET & $(\mathrm{CA})_{12}$ & $151-187$ & 12 & L37213 \\
\hline ILSTS049 & $\begin{array}{l}\text { caattttcttgtctctcecc } \\
\text { gctgaatcttgtcaaacagg }\end{array}$ & NED & $(\mathrm{CA})_{26}$ & $160-184$ & 11 & L37261 \\
\hline ILSTS065 & $\begin{array}{l}\text { getgcaaagagttgaacacc } \\
\text { aactattacaggaggctccc }\end{array}$ & PET & $(\mathrm{CA})_{22}$ & $105-135$ & 24 & L37269 \\
\hline ILSTSO58 & $\begin{array}{l}\text { gccttactaccatttccagc } \\
\text { catcetgactttggetgtgg }\end{array}$ & PET & $(\mathrm{GT})_{15}$ & $136-188$ & 17 & L37225 \\
\hline ILSTSO29 & $\begin{array}{l}\text { tgttttgatggaacacagcc } \\
\text { tggatttagaccagggttgg }\end{array}$ & PET & $(\mathrm{CA})_{19}$ & 148-191 & 3 & L37252 \\
\hline RM088 & $\begin{array}{l}\text { gatcctcttctgggaaaaagagac } \\
\text { cctgttgaagtgaaccttcagaa }\end{array}$ & FAM & $(\mathrm{CA})_{14}$ & 109-147 & 4 & U10392 \\
\hline ILSTS022 & $\begin{array}{l}\text { agtctgaaggcctgagaacc } \\
\text { cttacagtccttggggttgc }\end{array}$ & PET & $(\mathrm{GT})_{21}$ & $186-202$ & Ann & L37208 \\
\hline OARE129 & $\begin{array}{l}\text { aatccagtgtgtgaaagactaatccag } \\
\text { gtagatcaagatatagaatattttcaacacc }\end{array}$ & FAM & $(\mathrm{CA})_{14}$ & $130-175$ & 7 & L11051 \\
\hline ILSTS082 & $\begin{array}{l}\text { ttcgttcctcatagtgctgg } \\
\text { agaggattacaccaatcacc }\end{array}$ & PET & $(\mathrm{GT})_{17}$ & $100-136$ & 2 & L37236 \\
\hline RM4 & $\begin{array}{l}\text { cagcaaaatatcagcaaacct } \\
\text { ccacctgggaaggccttta }\end{array}$ & NED & $(\mathrm{CA})_{13}$ & $104-127$ & 15 & U32910 \\
\hline
\end{tabular}


Only forward primers at 5' end of each pair were labeled with one of the four fluorophore i.e., FAM (Blue), VIC (Green), NED (Yellow) and PET (red). Most of the microsatellite primers used was independent and belonged to different chromosome except (ILSTS30 and ILSTS082 on Chromosome 2, RM088 and Oar HH64 on chromosome 4, ILSTS008 and ETH225 on chromosome 14, OarFCB48 and ILSTS058 on chromosome 17). Polymerase Chain Reaction (PCR) was carried out on about 50-100 ng genomic DNA in a $25 \mu \mathrm{L}$ reaction volume. The reaction mixture consisted of $200 \mu \mathrm{M}$ of each dNTP, 50 $\mathrm{nM}$ KCL, $10 \mathrm{mM}$ Tris-HCL (pH 9.0), 0.1\% Triton X100, $2.0 \mathrm{mM} \mathrm{MgCl}_{2}, 0.75$ unit Taq DNA polymerase and $4 \mathrm{ng} \mu \mathrm{L}^{-1}$ of each primer using PTC-200 PCR machine (MJ Research). The 'touchdown' PCR protocol used with initial denaturation of $95^{\circ} \mathrm{C}$ for 3 min, 3 cycles of $95^{\circ} \mathrm{C}$ for $45 \mathrm{sec}$ and $60^{\circ} \mathrm{C}$ for $1 \mathrm{~min}, 3$ cycles of $95^{\circ} \mathrm{C}$ for $45 \mathrm{sec}$ and $57^{\circ} \mathrm{C}$ for $1 \mathrm{~min}, 3$ cycles of $95^{\circ} \mathrm{C}$ for $45 \mathrm{sec}$ and $54^{\circ} \mathrm{C}$ for $1 \mathrm{~min}$ and 20 cycles of $95^{\circ} \mathrm{C}$ for $45 \mathrm{sec}$ and $51^{\circ} \mathrm{C}$ for $1 \mathrm{~min}$ with final extension at $72^{\circ} \mathrm{C}$ for $5 \mathrm{~min}$. PCR products were loaded on to a $2 \%$ agarose gel, electrophoresed and visualized over UV light after ethidium bromide staining to detect the amplification.

Genotyping and allele detection: After determining the optimal pooling ratio and dilution ratio for a set of primers, the PCR products were mixed in ratio of 1:1.5:2:2 of FAM (blue), VIC (green), NED (yellow) and PET (red) labeled respectively. $0.5 \mu \mathrm{L}$ of this mixture was combined with $0.3 \mu \mathrm{L}$ of $\mathrm{Liz} 500$ as internal lane standard (Applied Biosystems) and $9.20 \mu \mathrm{L}$ of Hi-Di Formamide per sample. The resulting mixture was denatured by incubation for $5 \mathrm{~min}$ at $95^{\circ} \mathrm{C}$. These denatured samples were run on automated DNA sequencer of Applied Biosystems (ABI 3100 Avant). The electropherograms drawn through Gene Scan were used to extract DNA fragment sizing details using Gene Mapper software (version 3.0) (Applied Biosystems).

Statistical analysis: Genetic diversity within population was determined as the observed and expected number of alleles ${ }^{[17]}$ and Shanon's Information Index ${ }^{[22]}$ using Popgene software ${ }^{[39]}$. Observed and expected heterozygosity were calculated as per Levene ${ }^{[21]}$ as implemented in Arlequin software (version 3.11) ${ }^{[11]}$. A Monte Carlo method ${ }^{[14]}$, with forecasted chain length 1000000 was used to compute unbiased estimate of the exact probability ( $\mathrm{p}$-value) also implemented in the Arlequin. Wright's F-statistics ${ }^{[37]}$ were estimated in accordance with the procedures described by Weir and Cokerhan ${ }^{[35]}$ using the F-stat
2.9.3 $3^{[13]}$. A more appropriate measure of genetic variation within a population is gene diversity (average expected heterozygosity $)^{[27]}$ at each locus was calculated by the same software. Polymorphic Information Content (PIC) value was calculated according to Botstein et al. ${ }^{[5]}$ implemented in Cerevus 3.0.3 software package ${ }^{[17]}$. Hardy-Weinberg Equilibrium (HWE) at each locus was tested by Chi Squire $\left(\chi^{2}\right)$ goodness-of-fit test with Yat's Correction and significant test was done with Bonferroni corrections $^{[30]}$ to reduce the type I error, implemented in Cervus 3.0.3 software package ${ }^{[40]}$. Ewens-Watterson test was performed to test the neutrality for microsatellite markers; the statistics F (sum of square of allelic frequency) and limit (upper and lower) at $95 \%$ confidence region for the test were calculated using the algorithm by Manly ${ }^{[25]}$ using 1000 simulated samples and implemented in Popgene software package ${ }^{[39]}$. Bottleneck events were tested by three methods. The first method consisted of three excess heterozygosity tests developed by Cornuet and Luikart ${ }^{[9]}$; (i) sign test (ii) standardized difference test and (iii) wilcoxon sign-rank test. The probability distribution was established using 1000 simulations under three models; Infinite Allele Model (IAM), Step wise Mutation Model (SMM) and Two Phase Model of mutation (TPM).

The second method was the graphical representation of mode-shift indicator originally proposed by Luikart et al. ${ }^{[23]}$. Loss of rare alleles in bottlenecked populations is detected when one allele class have a higher number of alleles than the rare allele class $^{[23]}$. This test was rescaled so that frequency distribution of the allele frequency class would be based on equal 0.05 increments. These two methods were conducted using Bottleneck (version 1.2.03) ${ }^{[9]}$.

\section{RESULTS}

Various measures of genetic variation in terms of allele number, information index, PIC value and gene diversity are presented in Table 2. The observed number of alleles detected per locus ranged between 4 (ILST008, ETH225, OarJMP29 and RM088) to 24 (OarFCB304) with an overall mean of 10.12 \pm 5.46 .

Shannon's Information Index ${ }^{[22]}$, which measures the level of diversity, was sufficiently high with an overall mean of 1.603. Most of the studied loci showed the Polymorphic Information Content (PIC) values greater than 0.5 except a very few loci with an overall mean 0.647 .

The average expected heterozygosity was with an over all mean of 0.686 (Table 2). In Gohilwari goat breed, the mean effective number of alleles (4.78) was less than the half of the observed number of alleles (9.04) (Table 2). 
American J. Animal \& Vet. Sci., 4 (3): 49-57, 2009

Table 2: Number of alleles (Observed: $n_{a}$ and effective: $n_{e}$ ), Shannon's Information index (I) and Polymorphic Information Content (PIC) for Gohilwari goats

\begin{tabular}{lrrlll}
\hline Locus & \multicolumn{1}{c}{$\mathrm{n}_{\mathrm{a}}$} & \multicolumn{1}{c}{$\mathrm{n}_{\mathrm{e}}$} & $\mathrm{I}$ & PIC & $\begin{array}{l}\text { dene } \\
\text { diversity }\end{array}$ \\
\hline ILST008 & 4.0000 & 1.4122 & 0.5890 & 0.273 & 0.295 \\
ILSTS059 & 6.0000 & 2.5860 & 1.1348 & 0.541 & 0.628 \\
ETH225 & 4.0000 & 2.0306 & 0.9488 & 0.464 & 0.526 \\
ILSTS044 & 11.0000 & 2.0507 & 1.2654 & 0.498 & 0.520 \\
ILSTS002 & 12.0000 & 8.1337 & 2.2678 & 0.866 & 0.893 \\
OarFCB304 & 24.0000 & 9.0865 & 2.6726 & 0.883 & 0.902 \\
OarFCB48 & 11.0000 & 5.3629 & 1.9294 & 0.791 & 0.823 \\
OarHH64 & 12.0000 & 8.9476 & 2.2986 & 0.878 & 0.900 \\
OarJMP29 & 4.0000 & 1.0937 & 0.2293 & 0.084 & 0.087 \\
ILSTS005 & 7.0000 & 2.6523 & 1.2652 & 0.574 & 0.635 \\
ILSTS019 & 9.0000 & 5.2158 & 1.8465 & 0.784 & 0.818 \\
OMHC1 & 17.0000 & 10.6420 & 2.5340 & 0.899 & 0.916 \\
ILSTS087 & 13.0000 & 8.0222 & 2.2606 & 0.863 & 0.893 \\
ILSTS30 & 9.0000 & 5.9606 & 1.9362 & 0.811 & 0.842 \\
ILSTS34 & 6.0000 & 1.6329 & 0.8202 & 0.366 & 0.393 \\
ILSTS033 & 12.0000 & 3.7921 & 1.6797 & 0.701 & 0.747 \\
ILSTS049 & 9.0000 & 3.4047 & 1.5594 & 0.671 & 0.717 \\
ILSTS065 & 6.0000 & 3.1625 & 1.3018 & 0.628 & 0.697 \\
ILSTS058 & 23.0000 & 12.7735 & 2.8052 & 0.917 & 0.939 \\
ILSTS029 & 14.0000 & 5.5954 & 2.0448 & 0.801 & 0.830 \\
RM088 & 4.0000 & 1.8398 & 0.7801 & 0.388 & 0.464 \\
ILSTS022 & 6.0000 & 1.9523 & 0.9137 & 0.431 & 0.494 \\
OarAE129 & 9.0000 & 3.6736 & 1.6306 & 0.699 & 0.735 \\
ILSTS082 & 15.0000 & 5.9767 & 2.1839 & 0.818 & 0.840 \\
RM4 & 6.0000 & 2.6197 & 1.1667 & 0.544 & 0.628 \\
Mean & 10.1200 & 4.7848 & 1.6026 & 0.647 & 0.686 \\
SD & 5.4568 & 3.2091 & 0.6913 & 0.223 & 0.219 \\
\hline I Observed & & &
\end{tabular}

$\mathrm{n}_{\mathrm{a}}$ : Observed number of alleles; $\mathrm{n}_{\mathrm{e}}$ : Effective number of alleles ${ }^{[17]} ; \mathrm{I}$ : Shannon's Information index ${ }^{[22]}$; PIC: Polymorphic Information Content

Observed heterozygosity was lowest (0.074) at ETH225 locus and highest (0.979) at ILSTS082 locus with overall mean of 0.505 (Table 3). Expected heterozygosity ranged from 0.0869 (OarJMP29) to 0.935 (ILSTS058) with an over all mean of 0.684 . The observed heterozygosity was lower than that of the expected heterozygosity at most of the loci except OarJMP29, ILSTS029, OarAE129 and ILSTS058.

This breed of Goat also deviated from HWE at 15 loci out of 25 .

Ewens-Watterson test for neutrality of microsatellite markers: As the microsatellite markers have the specific property, as they are neutral to selection even the neutrality of each microsatellite marker was tested by Ewens-Watterson test for neutrality. In Gohilwari goat, $\mathrm{F}$ value (sum of square of allelic frequency) lied outside the lower and upper limit of $95 \%$ confidence region of expected $\mathrm{F}$ value at 6 loci (ILSTS044, ILSTS002, OarHH64, OarJMP29, OMHC1 and ILSTS030) (Table 4).
Table 3: Observed and expected heterozygosity with p-value, $F_{\text {is }}$ value for each microsatellite locus and mean estimate of different parameters for Gohilwari goats

\begin{tabular}{lllllrl}
\hline Locus & Obs. Het. & Exp. Het. & p-value & SD & $\mathrm{F}_{\text {is }}$ & HWE \\
\hline ILST008 & 0.25000 & 0.29496 & 0.22591 & 0.00043 & 0.154 & NS \\
ILSTS059 & 0.17391 & 0.62327 & 0.00000 & 0.00000 & 0.723 & $* * *$ \\
ETH225 & 0.07407 & 0.51712 & 0.00000 & 0.00000 & 0.859 & $* * *$ \\
ILSTS044 & 0.35417 & 0.51776 & 0.00049 & 0.00002 & 0.318 & ND \\
ILSTS002 & 0.56410 & 0.88844 & 0.00008 & 0.00001 & 0.368 & $* * *$ \\
OarFCB304 & 0.85366 & 0.90093 & 0.11483 & 0.00014 & 0.053 & NS \\
OarFCB48 & 0.79545 & 0.82288 & 0.51338 & 0.00049 & 0.034 & NS \\
OarHH64 & 0.66667 & 0.89759 & 0.00000 & 0.00000 & 0.259 & $* * *$ \\
OarJMP29 & 0.08824 & 0.08692 & 1.00000 & 0.00000 & -0.015 & NS \\
ILSTS005 & 0.20000 & 0.62996 & 0.00000 & 0.00000 & 0.685 & $* * *$ \\
ILSTS019 & 0.76744 & 0.81778 & 0.95550 & 0.00020 & 0.062 & NS \\
OMHC1 & 0.83333 & 0.91557 & 0.02936 & 0.00014 & 0.091 & NS \\
ILSTS087 & 0.42105 & 0.88702 & 0.00000 & 0.00000 & 0.529 & $* * *$ \\
ILSTS30 & 0.78261 & 0.84138 & 0.05658 & 0.00019 & 0.071 & $* * *$ \\
ILSTS34 & 0.25000 & 0.39167 & 0.00000 & 0.00000 & 0.364 & $* * *$ \\
ILSTS033 & 0.48889 & 0.74457 & 0.00000 & 0.00000 & 0.346 & NS \\
ILSTS049 & 0.43478 & 0.71405 & 0.00004 & 0.00001 & 0.394 & $* * *$ \\
ILSTS065 & 0.19149 & 0.69115 & 0.00000 & 0.00000 & 0.725 & $* * *$ \\
ILSTS058 & 0.70588 & 0.93547 & 0.00031 & 0.00001 & 0.248 & $* * *$ \\
ILSTS029 & 0.86364 & 0.83072 & 0.00000 & 0.00000 & -0.040 & $* * *$ \\
RM088 & 0.27907 & 0.46183 & 0.00012 & 0.00001 & 0.399 & $* * *$ \\
ILSTS022 & 0.38298 & 0.49302 & 0.01885 & 0.00012 & 0.225 & $* * *$ \\
OarAE129 & 0.82609 & 0.73579 & 0.53051 & 0.00041 & -0.124 & NS \\
ILSTS082 & 0.97917 & 0.84145 & 0.00067 & 0.00002 & -0.166 & NS \\
RM4 & 0.40000 & 0.62522 & 0.00016 & 0.00001 & 0.363 & $* * *$ \\
Mean & 0.50507 & 0.68426 & & & 0.264 & \\
SD & 0.28051 & 0.21917 & & & &
\end{tabular}

p-value for $\mathrm{F}_{\text {is }}$ within samples based on: 500 randomizations; Indicative adjusted nominal level (5\%) is: $0.00200 ;$ NS: Not Significant; $* * *$ : Significant at the $0.1 \%$ level

Table 4: The Ewens-Watterson test for Neutrality at 25 microsatellite loci in Gohilwari goat breed

\begin{tabular}{lcllll}
\hline Locus & $\mathrm{k}$ & Obs. F & SE & L95 & U95 \\
\hline ILST008 & 4 & 0.7081 & 0.0285 & 0.3099 & 0.8997 \\
ILSTS059 & 6 & 0.3867 & 0.0192 & 0.2255 & 0.7469 \\
ETH225 & 4 & 0.4925 & 0.0246 & 0.2929 & 0.8594 \\
ILSTS044 & $11^{*}$ & 0.4876 & 0.0067 & 0.1419 & 0.4505 \\
ILSTS002 & $12^{*}$ & 0.1229 & 0.0047 & 0.1239 & 0.3892 \\
OarFCB304 & 24 & 0.1101 & 0.0005 & 0.0634 & 0.1478 \\
OarFCB48 & 11 & 0.1865 & 0.0061 & 0.1369 & 0.4282 \\
OarHH64 & $12 *$ & 0.1118 & 0.0053 & 0.1309 & 0.4240 \\
OarJMP29 & $4 *$ & 0.9144 & 0.0253 & 0.3058 & 0.8607 \\
ILSTS005 & 7 & 0.3770 & 0.0165 & 0.1975 & 0.6835 \\
ILSTS019 & 9 & 0.1917 & 0.0106 & 0.1650 & 0.5654 \\
OMHC1 & $17 *$ & 0.0940 & 0.0022 & 0.0972 & 0.2776 \\
ILSTS087 & 13 & 0.1247 & 0.0035 & 0.1170 & 0.3431 \\
ILSTS30 & $9 *$ & 0.1678 & 0.0100 & 0.1694 & 0.5603 \\
ILSTS34 & 6 & 0.6124 & 0.0199 & 0.2307 & 0.7706 \\
ILSTS033 & 12 & 0.2637 & 0.0056 & 0.1269 & 0.4042 \\
ILSTS049 & 9 & 0.2937 & 0.0100 & 0.1626 & 0.5385 \\
ILSTS065 & 6 & 0.3162 & 0.0206 & 0.2275 & 0.7836 \\
ILSTS058 & 23 & 0.0783 & 0.0005 & 0.0631 & 0.1440 \\
ILSTS029 & 14 & 0.1787 & 0.0036 & 0.1103 & 0.3474 \\
RM088 & 4 & 0.5435 & 0.0277 & 0.3102 & 0.8886 \\
ILSTS022 & 6 & 0.5122 & 0.0198 & 0.2259 & 0.7648 \\
OarAE129 & 9 & 0.2722 & 0.0107 & 0.1638 & 0.5735 \\
ILSTS082 & 15 & 0.1673 & 0.0033 & 0.1068 & 0.3220 \\
RM4 & 6 & 0.3817 & 0.0205 & 0.2264 & 0.7560 \\
\hline : No. 0f & & &
\end{tabular}

k: No. of alleles; Obs. F: Observed sum of the squared of allelic frequency; L95, U95: The 95\% confidence interval upper and lower limit; SE: Standard error for observed F were calculated using 1000 simulated sample; *: F-value that outside the limit (lower and upper) of $95 \%$ confidence region 
Table 5: Test for null hypothesis under three microsatellite evolution models, (genetic bottleneck analysis)

\begin{tabular}{|c|c|c|c|c|c|}
\hline \multicolumn{2}{|l|}{ IAM } & \multicolumn{2}{|l|}{ TPM } & \multicolumn{2}{|l|}{ SMM } \\
\hline Expected & Observed & Expected & Observed & Expected & Observed \\
\hline \multicolumn{6}{|c|}{ Sign test: Number of loci with heterozygosity excess (probability) } \\
\hline $\begin{array}{l}15.02 \\
(0.57288)\end{array}$ & 15 & $\begin{array}{l}14.81 \\
(0.00543)\end{array}$ & 8 & $\begin{array}{l}14.79 \\
(0.00000)\end{array}$ & 3 \\
\hline \multicolumn{6}{|c|}{ Standard differences test: $\mathbf{T}_{2}$ values (probability) } \\
\hline $\begin{array}{l}0.643 \\
(0.26025)\end{array}$ & & $\begin{array}{l}-4.435 \\
(0.00000)\end{array}$ & & $\begin{array}{l}-11.841 \\
(0.00000)\end{array}$ & \\
\hline \multicolumn{6}{|c|}{ Wilcoxon-rank test (probability of heterozygosity excess) } \\
\hline 0.16270 & & 0.99201 & & 1.00000 & \\
\hline
\end{tabular}

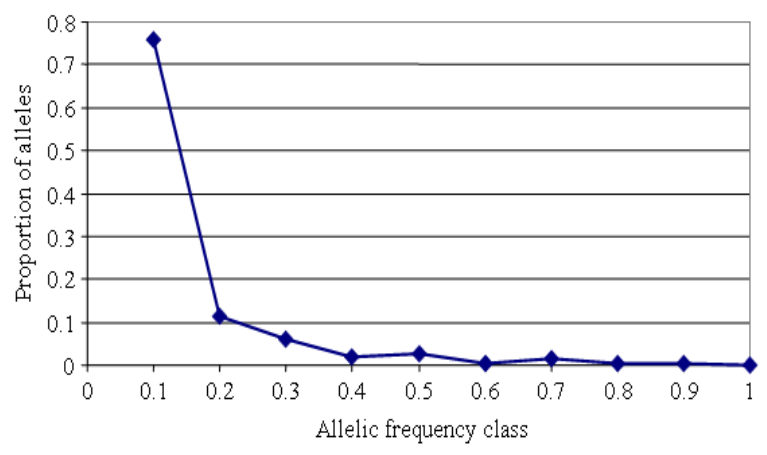

Fig. 1: Graphical representation of proportions of alleles and their distribution in Gohilwari goat breed

Genetic bottleneck: In Gohilwari goat, under Sign test, the expected numbers of loci with heterozygosity excess were 14.81 (TPM) and 14.79 (SMM) which were substantially higher than the observed numbers of loci 8 (TPM) and 3 (SMM) with heterozygosity excess (Table 5). So the null hypothesis that as the population is under Mutation-drift equilibrium was accepted. The expected number of loci (15.02) with heterozygosity excess was not significantly $(p>0.05)$ higher than the observed numbers of loci (15) with heterozygosity excess under IAM. So, the null hypothesis was again accepted under IAM for the sign test. Standard difference test $\left(\mathrm{T}_{2}\right.$ statistics) in this population provided the significant $(\mathrm{p}<0.05)$ gene diversity deficit under TPM (-4.435) and SMM (11.841) (Table 5). In IAM there was heterozygosity excess $(0.643)$ but not significant $(p>0.05)$. Positive values of the Bottleneck statistic $T_{2}$ are indicative of gene diversity excess caused by a recent reduction in effective population size, while negative value are consistent with a recent population expansion without immigration or immigration of some private (unique) alleles in population. Under Wilcoxon rank test, probability values of 0.1627 (IAM), 0.99201 (TPM) and $1.0(\mathrm{SMM})$ were non-significant $(\mathrm{p}<0.05)$. So, null hypothesis of mutation drift equilibrium was accepted under all the tests under all the three models.

The mode shift indicator i.e. qualitative method of estimation of bottleneck showed the normal L-shaped curve $^{[23]}$ (Fig. 1) in graphical representation of proportion of alleles verses class of frequency distribution.

\section{DISCUSSION}

All measures of genetic variation: observed number of alleles, effective number of alleles, Shannon's Information Index and PIC values showed that most of the studied loci were highly informative, indicating high polymorphism across the loci, thus suggesting suitability of these markers for genetic diversity studies in goats. Suitability of these studied markers was further strengthened as the number of alleles for each marker was higher, than the minimum number of four alleles recommended for microsatellite markers to be used in the estimation of genetic distance $^{[41]}$ in order to reduce the standard error.

The average expected heterozygosity i.e., gene diversity $^{[27]}$ was in the range of 0.3 to 0.8 as determined by Takezaki and $\mathrm{Ne}^{[34]}$ for markers to be useful in measuring genetic variation in a population.

Overall mean observed heterozygosity was lower than the overall mean expected heterozygosity. Most of the loci showed the heterozygote deficit as also depicted by $F_{\text {is }}$ value (Table 3 ).

Mean number of alleles observed over a range of loci in different populations is considered to be a reasonable indicator of genetic variation within the populations $^{[31]}$. This breed of goat showed the drastic low number of the effective number of alleles (even lower than half) than the observed number of alleles. This is due to very low frequency of most of the alleles at each locus and a very few alleles might have contributed the major part of the allelic frequency at each locus.

Even these revealed the high level of allelic diversity; a more appropriate measure of genetic variation within a population is gene diversity (average expected heterozygosity $)^{[27]}$. Overall mean of 0.686 (Table 2) of gene diversity was higher to the value reported in Swiss goat breeds (0.51 to 0.58) for 20 microsatellite $\operatorname{loci}^{[32]}$ and 11 indigenous south east Asian goats $(0.43-0.60)^{[3]}$ but is slightly lower than those reported in Chinese goat breeds (0.777-0.823) for 6 microsatellite loci ${ }^{[38]}$.

Another measure of genetic variation is observed heterozygosity. This population had higher mean observed heterozygosity than what was observed in 
Jakhrana and Marwari ${ }^{[19]}$, Attapady ${ }^{[1]}$ and many other Asian goats ${ }^{[3]}$ but lower in Chegu breed of goat ${ }^{[4]}$. Higher genetic variation in this studied breed may be due to its large effective population size, immigration of new gene due to intermixing of different population and low selection pressure. Breeding policies and different crossbreeding programmes might have contributed to higher genetic variation in Gohilwari goat population.

Majority of loci in this breed exhibited deficiency of heterozygosity at majority of loci. Overall mean $\mathrm{F}_{\text {is }}$ value of 0.264 was significantly different from zero. Significant heterozygote deficiency has been also reported in other studies of goat ${ }^{[3,42]}$. Heterozygote deficiency in this breed of goat could be due to one or more of the following reasons: segregation of nonamplifying (null) allele, Wahlund effect or inbreeding. However distinguishing among these was generally difficult $^{[7]}$. Null alleles arise more in case of heterologous primer (Microsatellite of different species) leads to underestimation of heterozygosity but Callen $e t$ $a l .^{[8]}$ identified null alleles using homologous microsatellite primers. This may be due to Wahlund effect or the fact that few bucks were used for the whole and nearby villages in the breeding region for breeding.

Deviation from HWE had also been reported in many other studies. Kim et al. ${ }^{[43]}$ reported HWE deviations in Korean, Chinese and Saanen goats. The main reasons for the deviation from HWE are most likely the genetic drift; non-random mating, nonamplifying alleles or the population might be divided into a series of closely related or inbred family groups.

In Ewens-Watterson test for neutrality for markers the observed loci, which lied outside the limit of $95 \%$ confidence region, were not neutral and may be linked with some selection traits. If a neutral allele statistically associated with a selected allele at another locus or genes where selection is operating significantly may be carried along and alleles cannot be separated from their genetic background. This phenomenon is known as hitchhiking. Genetic hitchhiking can be potent force in changing allelic frequency and heterozygosity.

Maynard-Smith and Haigh ${ }^{[26]}$ first suggested that molecular polymorphism may be modified by hitchhiking of neutral alleles adjacent to loci undergoing allelic substitution. Potentially one of the most important effects of hitchhiking is the reduction of heterozygosity of such molecular variation in area of low recombination due to selective sweeps at some of these loci substantially low level of heterozygosity has been observed (Table 3 ). In another specific study, Haiguo et $a l .^{[15]}$ found that the some alleles of
Microsatellite markers (ETH10 and IDVGA46) was linked to beef performance of cattle and showed positive or negative correlation with the different beef performance of cattle. Microsatellite ETH10 was also found linked to milk production performance in cattle $^{[18]}$. In this study, microsatellite that were found not neutral or linked to some selective trait must be further investigated for association to selective traits. This may help in MAS (marker assisted selection) in breeding programmes if the association to selective traits is established.

Genetic bottleneck: Genetic bottleneck occurs when population experiences some temporary reduction in size. This may influence distribution of genetic variation within and among populations. Loss of genetic diversity may reduce the potential of small populations to respond to selective pressure ${ }^{[2]}$ and increased inbreeding may reduce population viability $^{[20,28,36]}$.

The three tests (sign test, standard difference test and wilcoxon rank test) under these three model (IAM, TPM and SMM) for heterozygosity excess can detect the bottleneck for only a short duration of time after a bottleneck has been initiated. These are the quantitative test $^{[9]}$ that can detect bottleneck up to 50-250 generations. As discussed above, the null hypothesis of mutation drift equilibrium was accepted overall, there was no serious recent genetic bottleneck in Gohilwari goat breed.

In case of existence of bottleneck event the rare alleles are lost more often than the commonly occurring alleles and consequently there is a reduction in population size. Allele loss does not occur at the extreme of allele size distribution so the range in allele size remains constant. The non-bottleneck populations that are near mutation drift equilibrium are expected to have a large proportion of alleles in the range of low frequency and proportion of alleles decreasing or even nil at higher frequency class so normal L shaped curve. It can detect the recent bottleneck up to 40-80 generations only.

\section{CONCLUSION}

In conclusion, there was substantial genetic variation and polymorphism across studied loci in the Gohilwari breed of goat. And this population was not in Hardy-Weinberg equilibrium at most of the studied loci. This population was also receiving new genetic materials through introduction of immigrants. The 
strong inference that the Gohilwari breed of goat has not undergone bottleneck is also important for goat breeders and conservationists, as it suggests that any unique alleles present in this breed may not have been lost. Therefore, it can be recommended that withinbreed diversity is actively maintained to enable these extensively unmanaged stocks to adapt to future demands and conditions and there is ample scope for further improvement in its productivity through appropriate breeding strategies.

\section{ACKNOWLEDGEMENT}

We are most graceful to Hon'ble Vice-Chancellor, BAU, Kanke, Jharkhand (India) Dr. N. N. Singh for his constant promotional, progressive and financial support for the research work. We are extremely thankful to Dr. S. P. S. Ahlawat, Direcor, IVRI, Izzatnagar, for permitting to carry the research work at NBAGR, Karnal during his directorate ship at NBAGR, Karnal, Haryana (India). We also thank all those that have contributed to the field and lab work.

\section{REFERENCES}

1. Aggarwal, R.A.K., S.P. Dixit, N.K. Verma and S. Mathew et al., 2006. Genetic diversity in attappady breed of indian goat as analyzed with microsatellite markers. Korean J. Genet., 28: 237-242. http://www.reportworld.co.kr/data/paper/view/2570/P 2569036.html

2. Allendorf, F.W. and R.F. Leary, 1986. Heterozygosity and Fitness in Natural Populations of Animals. In: Conservation Biology: The Science of Scarcity and Diversity, Soule (Ed.). Sinauer, Sunderland, MA., pp: 57-76.

3. Barker, J.S.F., S.G. Tan, S.S. Moore, T.K. Mukherjee, L.J. Matheson and O.S. Selvaraj, 2001. Genetic variation within and relationships among populations of Asian goats (Capra hircus). J. Anim. Breed. Genet., 21: 213-233. http://www.ingentaconnect.com/content/bsc/jbg/20 01/00000118/00000004/art00296

4. Behl, R., N. Sheoran, J. Behl, R.K. Vijh and M.S. Tantia, 2003. Analysis of 22 heterologous microsatellite markers for genetic variability in Indian goats. Anim. Biotechnol., 14: 167-175. DOI: 10.1081/ABIO-120026486

5. Botstein, D., R.L. White, M. Skolnick and R.W. Davis, 1980. Construction of a genetic linkage map in man using restriction fragment length polymorphism. Am. J. Hum. Genet., 32: 39-48. PMID: 6247908
6. Bruford, M.W., D.J. Cheesman, T. Coote, H.A.A. Green, S.A. Haines, C. O'Ryan and T.R. Williams, 1996. Microsatellites and their application to conservation genetics. In: Molecular Genetic Approaches in Conservation, Smith, T.B. and R.K. Wayne (Eds). Oxford University Press, New York, pp: 278-297.

7. Christiansen, F.B., O. Frydenberg, A.O. Gyldenholm and V. Simonsen, 1974. Genetics of Zoraces populations. VI. Further evidence based on age group samples of a heterozygote deficit ESTIII polymorphism. Heriditas, 77: 225-236. DOI: 10.1111/j.1601-5223.1974.tb00936.x

8. Callen, D.F., A.D. Thompson, Y. Shen, HA. Phillips and R.I. Richards et al., 1993. Incidence and origin of 'null' alleles in the $(\mathrm{AC})_{\mathrm{n}}$ microsatellite marker. Am. J. Hum. Genet., 52: 922-927. PMID: 8488841

9. Cornuet, J.M. and G. Luikart, 1996. Description and power analysis of two tests for detecting recent population bottlenecks from allele frequency data. Genetics, 144: 2001-2014. PMID: 8978083

10. Eriksson, G., G. Namkoong and J.H. Roberds, 1993. Dynamic Gene Conservation for Uncertain Futures. For. Ecol. Manage., 62: 15-37. DOI: 10.1016/0378-1127(93)90039-P

11. Excoffier, L., G. Laval and S. Schneider, 2005. Arlequin ver. 3.0: An integrated software package for population genetics data analysis. Evolution. Bioinform. Online, 1: 47-50. PMID: 19325852

12. Glaubitz, J.C. and G.F. Moran, 2000. Genetic tools: The use of biochemical and molecular markers. In: Forest Conservation Genetics: Principles and Practice, Young, A.G., D. Boshier and T.J. Boyle (Eds.). CABI Publishing, Collingwood Australia, pp: 39-59.

13. Goudet, J., 2001. FSTAT, a program to estimate and test gene diversities and fixation indices (version 2.9.3). http://www.unil.ch/izea/softwares/fstat.html

14. Guo, S. and E. Thompson, 1992. Performing the exact test of Hardy-Weinberg proportion for multiple alleles. Biometrics, 48: 361-372. http://www.jstor.org/stable/2532296

15. Hauguo, J., C. Yang, Z. Yanqing, H. Bingzhou, Y. Changguo and L. Yunzai, 2004. Preliminary study of relationship of microsatellite DNA and beef performance traits of yanbian yellow cattle. Chinese J. Vet. Sci., 24: 285-288. http://d.wanfangdata.com.cn/Periodical_zgsyxb200 403027.aspx 
16. Kalinowski, S.T., M.L. Taper and T.C. Marshall, 2007. Revising how the computer program CERVUS accommodates genotyping error increases success in paternity assignment. Mol. Ecol., $\quad 16$ : 1099-1006. http://www.citeulike.org/group/7077/article/1125594

17. Kimura, M. and J.F. Crow, 1964. The number of alleles that can be maintained in a finite population. Genetics, 49: 725-738. PMID: 14156929

18. Kucerova, J., E. Nemcova, M. Stipkova, J. DvoRak, J. Frelich, J. Bousk and I. Vrtoka, 2004. Association between paternal microsatellite ETH10, Heterologous level of paternal microsatellite and milk production parameters in cattle. In proceeding of the xxi Gnetic day. 1-3 sept. Wroclaw Poland. Animal science papers and reports 22, Suppl. 2: 65-69.

19. Kumar, D., S.P. Dixit, R. Sharma, A.K. Pandey and G. Sirohi et al., 2005. Population structure, genetic variation and management of Marwari goats. Small Rumin. Res., 59: 41-48. DOI:10.1016/j.smallrumres.2004.11.013

20. Leberg, P.I., 1991. Influence of fragmentation and bottlenecks on genetic divergence of wild turkey populations. Conser. Biol., 5: 522-530. DOI: 10.1111/j.1523-1739.1991.tb00359.x

21. Levene, H., 1949. On a matching problem arising in genetics. Ann. Math. Stay, 20: 91-94. http://www.jstor.org/pss/2236806

22. Lewontin, R.C., 1972. The apportionment of human diversity. Evolution. Biol., 6: 381-398. http://www.dartmouth.edu/ biology/eeb/Cramer/R CL/Lewontin_plus.htm

23. Luikart, G.L., F.W. Allendrof, J.M. Cornuet and W.B. Sherwin, 1998. Distortion of allele frequency distributions provides a test for recent population bottlenecks. J. Heredity, 89: 238-247. http://jhered.oxfordjournals.org/cgi/content/abstrac $\mathrm{t} / 89 / 3 / 238$

24. MacHugh, D.E., R.T. Loftus, P. Cunningham and D.G. Bardley, 1998. Genetic structure of seven European cattle breeds assessed using 20 microsatellite markers. Anim. Genet., 29: 333-340. DOI: 10.1046/j.1365-2052.1998.295330.x

25. Manly, B.F.J., 1985. The Statistics of Natural Selection. Chapman and Hall, London, UK., pp: 484.

26. Maynard-Smith, J. and J. Haigh, 1974. The Hitchhiking effect of a favorable gene. Genet. Res., 23: 23-35. PMID: 4407212

27. Nei, M., 1987. Molecular Evolutionary Genetics. Columbia University Press, New York, USA., pp: $287-326$
28. Newman, D. and D. Pilson, 1997. Increased probability of extinction due to decreased genetic effective population size: Experimental populations of Clarkia pulchella. Evolution, 51: 354-362. http://d.wanfangdata.com.cn/NSTLQK_NSTL_QK 9739328.aspx

29. Rajora, O.P. and A. Mosseler, 2001a. Challenges and opportunities for conservation of forest genetic resources. Euphytica, 118: 197-212. DOI: 10.1023/A:1004150525384

30. Rice, W.R., 1989. Analysing tables of statistical tests. Evolution, 43: 223-225. http://www.usm.maine.edu/bio/courses/bio621/Ric e_sequential_bonferroni.pdf

31. MacHugh, D.E., M.D. Shriver, R.T. Loftus, P. Cunningham and D.G. Bardley, 1997. Microsatellite DNA variation and the evolution; domestication and phylogeography of taurine and zebu cattle (Bos Taurus and Bos indicus). Genetics, 146: 1071-1086.

http://www.genetics.org/cgi/content/abstract/146/3/1071

32. Saitbekova, N., C. Gaillard, G. Obexer-Ruff and G. Dolf, 1999. Genetic diversity in Swiss goat breeds based on microsatellite analysis. Anim. Genet., 30: 36-41. PMID: 10050281

33. Sambrook, J., E.F. Fritsch and T. Maniatis, 1989. Molecular Cloning: A Laboratory Manual. 2nd Edn., Cold Spring Harbor, Cold Laboratory Press, New York, USA.

34. Takezaki, N. and M. Nei, 1996. Genetic distances and reconstruction of phylogenetic trees from microsatellite DNA. Genetics, 144: 389-399. http://www.genetics.org/cgi/content/abstract/144/1/389

35. Weir, B.S. and C.C. Cockerham, 1984. Estimating F-statistics for the analysis of population structure. Evolution, $\quad 38$ : $1358-1370$. http://www.jstor.org/pss/2408641

36. Westemeier, R.L., J.D. Brawn, S.A. Simpson, T.L. Esker and R.W. Jansen Jeffery W. Walk, Eric L. Kershner, Juan L. Bouzat, Ken N. Paige. 1998. Tracking the long-term decline and recovery of an isolated population. Science, 282: 1695-1698. DOI: 10.1126/science.282.5394.1695

37. Wright, S., 1965. The interpretation of population structure by F-statistics with special regard to systems of mating. Evolution, 19: 395-420. http://www.citeulike.org/user/jbyoder/article/3289946

38. Yang, L., S.H. Zho, K. Li, Z.Z. Peng and G.W. Mongomery, 1999. Determination of genetic relationship among five indigenous Chinese goat breeds with six microsatellite markers. Anim. Genet., 30: 452-455. DOI: 10.1046/j.13652052.1999.00548.x 
39. Yeh, F.C., T. Boyle, Y. Ronagcai, Z. Ye and J.M. Xian, 1999. POPGENE version 3.1. http://www.ualberta.Ca/-Fyeh/Fyah

40. Kalinowaski, S. T.; Taper, M. L. and Marshall, T. C. (2007). Revising how the computer program CERVUS accommodates genotyping error increases success in paternity assignment. Mol. Ecology, 16: 1099-1106. DOI: $10.1111 / \mathrm{j} .1365-$ 294X.2007.03089.X

41. Barker, J. S. F. (1994). A global protocol for determining genetic distances among domestic livestock breeds. Proc. World Cong. Genet. Applied Livestock Prod., 21: 501-508.
42. Luikart, G., M.P. Biju-Duval, O. Ertugrul, Y. Zagdsuren, C. Maudet and P. Taberlet, 1999. Power of 22 microsatellite markers in fluorescent multiplexes for parentage testing in goats (Capra hircus). Anim. Genet., 30: 431-438. DOI: 10.1046/j.13652052.1999.00545.X

43. Kim, K.S., J.W. Yeo, J.W. Lee, J.W. Kim and C.B. Choi, 2002. Genetic diversity of goats from korea and china using microsatellite analysis. Asian-Aust. J. Anim. Sci.; 15: 461-465. http://www.ajas.info/include/file_download.asp?do wn_path $=$ manuscript $\&$ Fname $=15 \% 2$ D $70 \% 2$ Epdf 